\title{
PENERAPAN METODE FAILURE MODE AND EFFECT ANALYSIS (FMEA) DALAM MENGIDENTIFIKASI MASALAH KERUSAKAN PRODUK PAKAN AYAM PADA PT. JAPFA COMFEED INDONESIA, TBK UNIT LAMPUNG
}

\author{
${ }^{1}$ Marcelly Widya Wardana, ${ }^{2}$ Sulastri, ${ }^{3}$ Siti Hasanah \\ ${ }^{1,2,3}$ Program Studi Teknik Industri, Fakultas Teknik, Universitas Malahayati \\ Jl. Pramuka No.27 Kemiling, Bandar Lampung \\ e-mail: marcelly@malahayati.ac.id
}

\begin{abstract}
PT. Japfa Comfeed Indonesia, Tbk Unit Lampung is a company engaged in the field of animal feed with two types of products, namely pellet and crumble. The real condition that often occurs in this company is that there is a final product that has problems in animal feed that is not in accordance with predetermined quality standards. The purpose of this study is to analyze failures that cause product defects by using the Failure Mode and Effect Analysis (FMEA) method, getting the risk of the biggest production process failure in the RPN (Risk Priority Number) value, and proposing improvements for subsequent production. The method used in this study uses statistical tools in the form of check sheets, $p$ control chart and Cause Failure Mode Effect (CMFE) analysis. The results of the control chart analysis show that chicken feed is within the control limit, and the highest Risk Priority Number (RPN) value is the filter with a value of 100 RPN so that the pellet can pass the final stage. To overcome this problem, the proposed improvement is to add a filter to the crumble machine and then carry out routine maintenance and inspection.
\end{abstract}

Key words : CMFE; FMEA; p control chart; RPN

\section{PENDAHULUAN}

Suatu perusahaan tidak lepas dari kualitas produk yang dihasilkannya. Konsumen tentu berharap bahwa barang yang dibelinya akan dapat memenuhi kebutuhan dan keinginannya, sehingga konsumen berharap bahwa produk tersebut memiliki kondisi yang baik serta terjamin (Lawrence dkk., 2016). Oleh karena itu, perusahaan harus melihat dan menjaga agar kualitas produk yang dihasilkan terjamin serta diterima oleh konsumen (Hofmann \& Oldehaver, 2016). PT. Japfa Comfeed Indonesia, Tbk Unit Lampung merupakan salah satu perusahaan yang bergerak dalam bidang pakan ternak dengan dua jenis produk yaitu seperti pellet dan crumble. Kondisi nyata yang sering terjadi pada perusahaan ini adalah terdapat produk akhir yang bermasalah pada pakan ternak yang tidak sesuai dengan standar kualitas yang telah ditentukan. Tujuan penelitian ini adalah menganalisa kegagalan yang menyebabkan cacat produk dengan menggunakan metode Failure Mode and Effect Analysis (FMEA). FMEA sendiri adalah sebuah teknik rekayasa yang digunakan untuk menetapkan, mengidentifikasi, dan untuk menghilangkan kegagalan yang diketahui, permasalahan, error, dan sejenisnya dari sebuah sistem, desain, proses, dan atau jasa sebelum mencapai konsumen (Klochkov, Its \& Vasilieva, 2016; Liu, 2016).

\section{METODE PENELITIAN}

Tahapan penelitian diawali dengan mengumpulkan data menggunakan check sheet, dilanjutkan dengan perhitungan peta kendali p dan membuat grafiknya, analisis Cause Failure Mode Effect (CMFE) dan tahap terakhir membuat tabel FMEA beserta usulan rencana perbaikan (recommended action).

Dalam perusahaan pabrik, istilah kualitas diartikan sebagai faktor-faktor yang terdapat dalam suatu barang/hasil yang menyebabkan barang/hasil tersebut sesuai dengan tujuan untuk apa barang atau hasil dimaksudkan atau dibutuhkan (Assauri, 1993). Menurut W. Edwards Deming (2014) menjelaskan bahwa kualitas merupakan perbaikan secara berkesinambungan pada sebuah sistem yang stabil. Menurut American Society for Quality Control, kualitas adalah totalitas bentuk dan karakteristik barang atau jasa yang menunjukkan kemampuannya untuk memuaskan kebutuhan-kebutuhan yang tampak jelas maupun yang tersembunyi (Heizer, 2006; Roy, Modak \& Dan, 2017). Menurut Schroeder (2017), untuk mengimplementasikan 
perencanaan, pengendalian dan pengembangan kualitas diperlukan beberapa tahapan- tahapan yaitu mendefinisikan karakteristik (atribut) kualitas, menentukan bagaimana cara mengukur setiap karakteristik, menetapkan standar kualitas, menetapkan program inspeksi, mencari dan memperbaiki penyebab kualitas yang rendah dan terus-menerus melakukan perbaikan.

Pengendalian kualitas statistik dilakukan dengan menggunakan alat bantu statistik yang merupakan teknik penyelesaian masalah yang digunakan untuk memonitor, mengendalikan, menganalisis, mengelola dan memperbaiki produk dan proses menggunakan metode-metode statistik (Nasution, 2005). Menurut Chase (2017), Statistical Quality Control diartikan sebagai berikut : "Statistical Quality Control is a number of different techniques designed to evaluate quality from a conformance view". Pengendalian kualitas secara statistik menggunakan 7 (tujuh) alat statatistik utama yang dapat digunakan sebagai alat bantu untuk mengendalikan kualitas, antara lain yaitu: check sheet, histogram, control chart, diagram pareto, diagram sebab akibat, scatter diagram dan diagram proses (Heizer, 2006; Weckenmann, Akkasoglu, \& Werner, 2015). Peta kendali atribut digunakan untuk mengendalikan kualitas produk selama proses produksi yang tidak dapat diukur tetapi dapat dihitung, sehingga kualitas produk dapat dibedakan dalam karakteristik baik atau buruk, berhasil atau gagal (Montgomery, 2001). Peta kendali kerusakan ( $p$ chart) digunakan untuk menganalisis banyaknya barang yang ditolak yang ditemukan dalam pemeriksaan atau sederetan pemeriksaan terhadap total barang yang diperiksa. Untuk membuat peta kendali p ini dapat digunakan rumus-rumus sebagai berikut (Montgomery, 2001):

$$
\mathrm{P}=\frac{\mathrm{np}}{\mathrm{n}}
$$

Keterangan: $\quad \mathrm{np}=$ Jumlah gagal dalam sub group

$\mathrm{n} \quad=$ jumlah yang diperiksa dalam sub group

$$
\mathrm{CL}=\bar{P}=\frac{\sum n p}{\sum n}
$$

Keterangan : $\quad \sum \mathrm{np}=$ jumlah total yang rusak

$$
\begin{aligned}
& \sum \mathrm{n}=\text { jumlah total yang diperiksa } \\
& \mathrm{CL}=\text { batas kontrol } \\
& \mathrm{UCL}=\text { batas control atas } \\
& \mathrm{LCL}=\text { batas control bawah } \\
& \mathrm{UCL}=\bar{P}+3 \sqrt{\frac{p_{(1-\bar{P})}}{n}} \\
& \mathrm{LCL}=\bar{P}-3 \sqrt{\frac{p(1-\bar{p})}{n}}
\end{aligned}
$$

Failure Mode And Effect Analysis (FMEA) merupakan suatu metode yang bertujuan untuk mengevaluasi desain sistem dengan mempertimbangkan bermacam-macam model kegagalan dari sistem yang terdiri dari komponen komponen dan menganalisis pengaruh-pengaruhnya terhadap keandalan sistem tersebut (Irianto, 2010). Dengan penelusuran pengaruh-pengaruh kegagalan komponen sesuai dengan level sistem, item-item khusus yang kritis dapat dinilai dan tindakan-tindakan perbaikan diperlukan untuk memperbaiki desain dan mengeliminasi atau mereduksi probabilitas dari mode-mode kegagalan yang kritis. Dalam FMEA, dapat dilakukan perhitungan Risk Priority Number (RPN) untuk menentukan tingkat kegagalan tertinggi (Kim \& Zuo, 2018). RPN merupakan produk matematis dari keseriusan effect (severity), kemungkinan terjadinya cause akan menimbulkan kegagalan yang berhubungan dengan effect (occurrence), dan kemampuan untuk mendeteksi kegagalan sebelum terjadi (detection) (Irianto, 2010). RPN dapat ditunjukkan dengan persamaan sebagai berikut :

$$
\mathrm{RPN}=\text { Severity } \mathrm{x} \text { Occurrence } \mathrm{x} \text { Detection }
$$


Tabel 1. Rating untuk severity, occurrence dan detection

\begin{tabular}{|c|c|c|c|}
\hline RATING & $\begin{array}{c}\text { CRITERIA OF } \\
\text { SEVERITY EFFECT }\end{array}$ & $\begin{array}{l}\text { PROBABILITY OF } \\
\text { OCCURRENCE }\end{array}$ & $\begin{array}{c}\text { DETECTION DESIGN } \\
\text { CONTROL }\end{array}$ \\
\hline 10 & $\begin{array}{l}\text { Tidak berfungsi sama } \\
\text { sekali }\end{array}$ & $\begin{array}{l}\text { Lebih besar dari } 100 \text { per } \\
\text { seribu kali penggunaan }\end{array}$ & Tidak mampu terdeteksi \\
\hline 9 & $\begin{array}{l}\text { Kehilangan fungsi } \\
\text { utama dan menimbulkan } \\
\text { peringatan }\end{array}$ & $\begin{array}{l}50 \text { per seribu kali } \\
\text { penggunaan }\end{array}$ & $\begin{array}{l}\text { Kesempatan yang sangat } \\
\text { rendah dan sangat sulit } \\
\text { untuk terdeteksi }\end{array}$ \\
\hline 8 & $\begin{array}{l}\text { Kehilangan fungsi } \\
\text { utama }\end{array}$ & $\begin{array}{l}20 \text { per seribu kali } \\
\text { penggunaan }\end{array}$ & $\begin{array}{l}\text { Kesempatan yang sangat } \\
\text { rendah dan sulit untuk } \\
\text { terdeteksi }\end{array}$ \\
\hline 7 & $\begin{array}{l}\text { Pengurangan fungsi } \\
\text { utama }\end{array}$ & $\begin{array}{l}10 \text { per seribu kali } \\
\text { penggunaan }\end{array}$ & $\begin{array}{l}\text { Kesempatan yang sangat } \\
\text { rendah untuk terdeteksi }\end{array}$ \\
\hline 6 & $\begin{array}{l}\text { Kehilangan kenyamanan } \\
\text { fungsi penggunaan }\end{array}$ & $\begin{array}{l}5 \text { per seribu kali } \\
\text { penggunaan }\end{array}$ & $\begin{array}{l}\text { Kesempatan yang } \\
\text { rendah untuk terdeteksi }\end{array}$ \\
\hline 5 & $\begin{array}{l}\text { Mengurangi } \\
\text { kenyamanan fungsi } \\
\text { penggunaan }\end{array}$ & $\begin{array}{l}2 \text { per seribu kali } \\
\text { penggunaan }\end{array}$ & $\begin{array}{l}\text { Kesempatan yang } \\
\text { sedang untuk terdeteksi }\end{array}$ \\
\hline 4 & $\begin{array}{l}\text { Perubahan fungsi dan } \\
\text { banyak pekerja } \\
\text { menyadari adanya } \\
\text { masalah }\end{array}$ & $\begin{array}{l}1 \text { per seribu kali } \\
\text { penggunaan }\end{array}$ & $\begin{array}{l}\text { Kesempatan yang cukup } \\
\text { tinggi untuk terdeteksi }\end{array}$ \\
\hline 3 & $\begin{array}{l}\text { Tidak terdapat efek dan } \\
\text { pekerja menyadari } \\
\text { adanya masalah }\end{array}$ & $\begin{array}{l}0,5 \text { per seribu kali } \\
\text { penggunaan }\end{array}$ & $\begin{array}{l}\text { Kesempatan yang tinggi } \\
\text { untuk terdeteksi }\end{array}$ \\
\hline 2 & $\begin{array}{l}\text { Tidak terdapat efek dan } \\
\text { pekerja tidak menyadari } \\
\text { adanya masalah }\end{array}$ & $\begin{array}{l}\text { Lebih kecil dari } 0,1 \text { per } \\
\text { seribu kali penggunaan }\end{array}$ & $\begin{array}{l}\text { Kesempatan yang sangat } \\
\text { tinggi untuk terdeteksi }\end{array}$ \\
\hline 1 & Tidak ada efek & $\begin{array}{l}\text { Probability of } \\
\text { Occurrence }\end{array}$ & Pasti terdeteksi \\
\hline
\end{tabular}

\section{HASIL DAN PEMBAHASAN}

Berikut ini adalah sampel data kerusakan produk pakan ayam Tabel 1.

Tabel 1. Pengumpulan data dengan check sheet

\begin{tabular}{cccccc}
\hline Hari Ke- & $\begin{array}{c}\text { Sampel } \\
\text { (gr) }\end{array}$ & $\begin{array}{c}\text { Jenis Kerusakan } \\
\text { Tepung Tinggi }\end{array}$ & $\begin{array}{c}\text { Jumlah } \\
\text { Pellet Dalam Bentuk } \\
\text { Crumble }(\mathbf{g r})\end{array}$ & $\begin{array}{c}\text { Persentase } \\
\text { Kerusakan } \\
\text { (gr) }\end{array}$ & $\begin{array}{c}\text { Kerusakan } \\
(\%)\end{array}$ \\
\hline $\mathbf{1}$ & 100 & 11 & 3 & 14 & 0.14 \\
$\mathbf{2}$ & 100 & 9 & 3 & 12 & 0.12 \\
$\mathbf{3}$ & 100 & 11 & 2 & 13 & 0.13 \\
$\mathbf{4}$ & 100 & 11 & 4 & 15 & 0.15 \\
$\mathbf{5}$ & 100 & 10 & 2 & 12 & 0.12 \\
$\mathbf{6}$ & 100 & 9 & 5 & 14 & 0.14 \\
$\mathbf{7}$ & 100 & 11 & 2 & 13 & 0.13 \\
$\mathbf{8}$ & 100 & 9 & 4 & 13 & 0.13 \\
$\mathbf{9}$ & 100 & 11 & 4 & 15 & 0.15 \\
$\mathbf{1 0}$ & 100 & 10 & 5 & 15 & 0.15 \\
$\mathbf{1 1}$ & 100 & 10 & 4 & 14 & 0.14 \\
$\mathbf{1 2}$ & 100 & 10 & 5 & 15 & 0.15 \\
$\mathbf{1 3}$ & 100 & 8 & 5 & 13 & 0.13 \\
$\mathbf{1 4}$ & 100 & 11 & 2 & 13 & 0.13 \\
$\mathbf{1 5}$ & 100 & 9 & 4 & 13 & 0.13 \\
\hline
\end{tabular}




\begin{tabular}{cccccc}
\hline & & & & & \\
\hline $\mathbf{1 6}$ & 100 & 10 & 3 & 13 & 0.13 \\
$\mathbf{1 7}$ & 100 & 11 & 3 & 14 & 0.14 \\
$\mathbf{1 8}$ & 100 & 10 & 4 & 14 & 0.14 \\
$\mathbf{1 9}$ & 100 & 11 & 3 & 14 & 0.14 \\
$\mathbf{2 0}$ & 100 & 8 & 3 & 11 & 0.11 \\
$\mathbf{2 1}$ & 100 & 11 & 4 & 15 & 0.15 \\
$\mathbf{2 2}$ & 100 & 10 & 2 & 12 & 0.12 \\
$\mathbf{2 3}$ & 100 & 11 & 5 & 16 & 0.16 \\
$\mathbf{2 4}$ & 100 & 9 & 3 & 12 & 0.12 \\
$\mathbf{2 5}$ & 100 & 9 & 87 & 12 & 0.12 \\
Jumlah & 2500 & 250 & 337 & 3.37 \\
\hline
\end{tabular}

Berdasarkan pengumpulan data di atas, selanjutnya dilakukan perhitungan untuk membuat peta kendali $\mathrm{p}$, dan hasil perhitungan selengkapnya dapat dilihat pada tabel berikut.

Tabel 2. Hasil perhitungan peta kendali $\mathrm{p}$

\begin{tabular}{ccccccc}
\hline $\begin{array}{c}\text { Hari } \\
\text { Ke- }\end{array}$ & $\begin{array}{c}\text { Sampel } \\
\text { (gr) }\end{array}$ & $\begin{array}{c}\text { Jumlah Kerusakan } \\
\text { (gr) }\end{array}$ & $\begin{array}{c}\text { Persentase } \\
\text { Kerusakan }(\mathbf{\%})\end{array}$ & LCL & CL & UCL \\
\hline $\mathbf{1}$ & 100 & 14 & 0.14 & 0.03 & 0.13 & 0.23 \\
$\mathbf{2}$ & 100 & 12 & 0.12 & 0.03 & 0.13 & 0.23 \\
$\mathbf{3}$ & 100 & 13 & 0.13 & 0.03 & 0.13 & 0.23 \\
$\mathbf{4}$ & 100 & 15 & 0.15 & 0.03 & 0.13 & 0.23 \\
$\mathbf{5}$ & 100 & 12 & 0.12 & 0.03 & 0.13 & 0.23 \\
$\mathbf{6}$ & 100 & 14 & 0.14 & 0.03 & 0.13 & 0.23 \\
$\mathbf{7}$ & 100 & 13 & 0.13 & 0.03 & 0.13 & 0.23 \\
$\mathbf{8}$ & 100 & 13 & 0.13 & 0.03 & 0.13 & 0.23 \\
$\mathbf{9}$ & 100 & 15 & 0.15 & 0.03 & 0.13 & 0.23 \\
$\mathbf{1 0}$ & 100 & 15 & 0.15 & 0.03 & 0.13 & 0.23 \\
$\mathbf{1 1}$ & 100 & 14 & 0.14 & 0.03 & 0.13 & 0.23 \\
$\mathbf{1 2}$ & 100 & 15 & 0.15 & 0.03 & 0.13 & 0.23 \\
$\mathbf{1 3}$ & 100 & 13 & 0.13 & 0.03 & 0.13 & 0.23 \\
$\mathbf{1 4}$ & 100 & 13 & 0.13 & 0.03 & 0.13 & 0.23 \\
$\mathbf{1 5}$ & 100 & 13 & 0.13 & 0.03 & 0.13 & 0.23 \\
$\mathbf{1 6}$ & 100 & 13 & 0.13 & 0.03 & 0.13 & 0.23 \\
$\mathbf{1 7}$ & 100 & 14 & 0.14 & 0.03 & 0.13 & 0.23 \\
$\mathbf{1 8}$ & 100 & 14 & 0.14 & 0.03 & 0.13 & 0.23 \\
$\mathbf{1 9}$ & 100 & 14 & 0.14 & 0.03 & 0.13 & 0.23 \\
$\mathbf{2 0}$ & 100 & 11 & 0.11 & 0.03 & 0.13 & 0.23 \\
$\mathbf{2 1}$ & 100 & 15 & 0.15 & 0.03 & 0.13 & 0.23 \\
$\mathbf{2 2}$ & 100 & 12 & 0.12 & 0.03 & 0.13 & 0.23 \\
$\mathbf{2 3}$ & 100 & 16 & 0.16 & 0.03 & 0.13 & 0.23 \\
$\mathbf{2 4}$ & 100 & 12 & 0.12 & 0.03 & 0.13 & 0.23 \\
$\mathbf{2 5}$ & 100 & 12 & 0.12 & 0.03 & 0.13 & 0.23 \\
Jumlah & 2500 & 337 & 3.37 & & & \\
\hline & & & & & & \\
\hline
\end{tabular}

Dari hasil perhitungan tabel di atas, maka selanjutnya dapat dibuat grafik peta kendali p pada Gambar 1 berikut : 


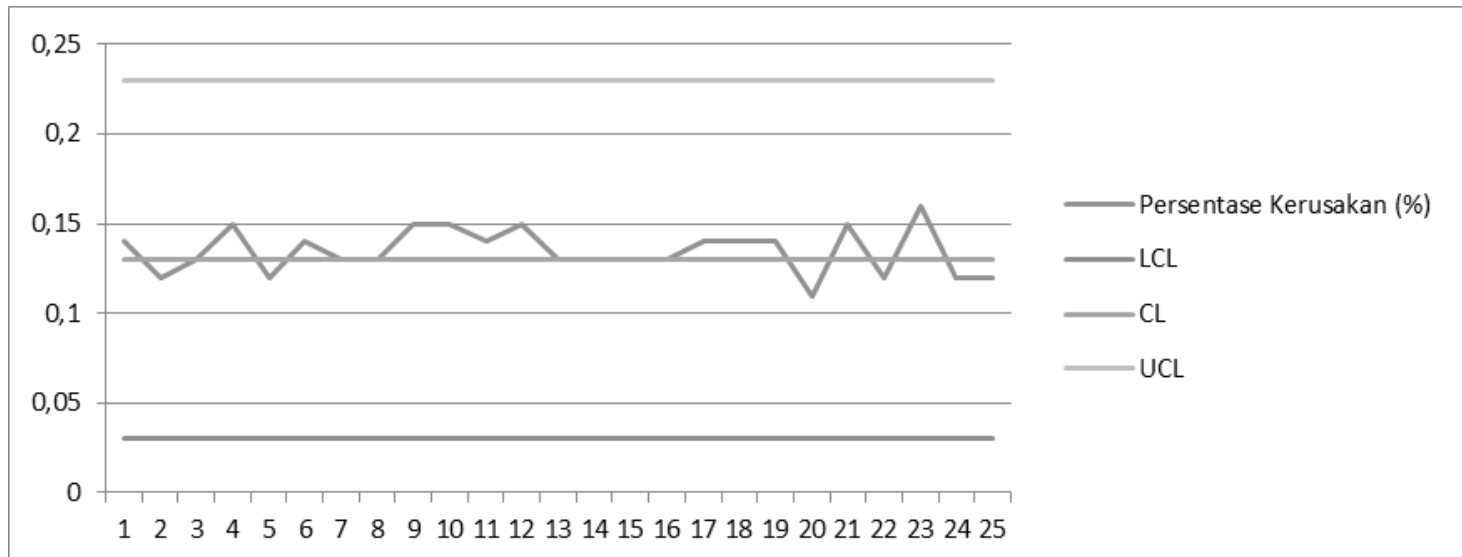

Gambar 1. Grafik peta kendali $\mathrm{p}$

Berdasarkan grafik peta kendali $\mathrm{p}$ di atas dapat dilihat bahwa titik-titik data yang diperoleh setelah pengujian sampel tersebut menggambarkan kerusakan yang terjadi sangat bervariasi setiap harinya. Hal ini disebabkan karena banyak faktor baik itu mesin, manusia atau metode kerjanya, sehingga tidak setiap harinya hasil produksi pakan ayam selalu sama kualitasnya. Tahap berikutnya adalah analisis Cause Failure Mode Effect (CMFE), yaitu analisis sebab akibat yang digunakan untuk menelusuri jenis kerusakan pakan ayam yang terjadi dengan hasil sebagai berikut :

\section{Cacat Tepung Tinggi}

Masalah tepung tinggi ini biasanya terjadi pada produk akhir untuk jenis pellet dan crumble. Pada saat pemeriksaan sampel produk yang seharusnya berjenis pellet dan crumble ditemukan kadar tepung yang tinggi sehingga produk tersebut tidak layak untuk dikonsumsi oleh ternak. Penyebab dari terjadinya tepung tinggi ini diantaranya adalah:

a. Faktor Manusia

1) Kurang kedisiplinan pekerja membuat produk akhir cacat karena ada masalah, jenuh, malas, kelelahan dan mengobrol.

2) Kurangnya pengawasan dari atasan membuat pekerja kurang disiplin.

b. Faktor Mesin

1) Dies pada mesin crumble sudah lama terpakai, sehingga dapat menurunkan daya tahan (durability) dari pakan ayam.

2) Saringan hummer mill bocor, sehingga mengalami menurunan dalam kinerja mesin tersebut.

c. Faktor Material

1) Palm oilyang terkandung di dalam tepung terlalu tinggi sehingga dapat membuat pakan ternak cepat tengik.

2) Bahan baku jagung basahsehingga kadar tepung saat diproduksi tinggi

d. Faktor Lingkungan

Suara mesin dan getaran didalam pabrik dapat menurunkan konsetrasi pegawai dalam mengawasi proses produksi.

2. Cacat terdapat pellet pada bentuk crumble

Pakan ternak yang berbentuk crumble merupakan bentuk yang awalnya pellet kemudian diproses kembali dengan crumbling untuk mendapatkan ukuran yang lebih kecil lagi dari pellet berupa pecahan/butiran. Namun dalam masalah ini saat pemeriksaan sampel produk bentuk crumble masih ditemukan ransum yangberjenis pellet utuh. Penyebab dari terdapat pellet pada bentuk crumble ini diantaranya adalah: 
a. Faktor Manusia

1) Operator menyetting pisau pada mesin presskurang pas panjang pendeknya.

2) Operator kurang disiplin dalam perawatan mesin sehingga teflon aus.

b. Faktor Mesin

1) Ayakan pada mesin crumble hanya terdapat satu lapis sehingga masih terdapat pellet yang lolos ikut lanjut sampai pada proses bagging off.

2) Proses penyettingan mesin crumbletidak tepat maka saat akan digunakan kurang maksimal.

c. Faktor Lingkungan

Suara mesin dan getaran didalam pabrik dapat menurunkan konsetrasi pegawai dalam mengawasi proses produksi.

Untuk membuat Failure Modes and Effect Analysis (FMEA), data berasal dari hasil analisis akar permasalahan yang didokumentasikan CMFE.

Tabel 3. Uraian Failure Mode and Effect Analysis (FMEA)

\begin{tabular}{|c|c|c|c|c|c|c|c|c|c|}
\hline $\begin{array}{l}\text { Jenis } \\
\text { Cacat }\end{array}$ & $\begin{array}{c}\text { Component } \\
\text { /Item } \\
\text { or Process }\end{array}$ & $\begin{array}{c}\text { Potentia } \\
\text { l Failure } \\
\text { Mode }\end{array}$ & $\begin{array}{c}\text { Potential } \\
\text { Effect of } \\
\text { Failure }\end{array}$ & $\sqrt[x]{q}$ & $\begin{array}{c}\text { Potential } \\
\text { Cause of } \\
\text { Failure }\end{array}$ & ฉి & Control & 걱 & RPN \\
\hline \multirow[t]{6}{*}{$\begin{array}{l}\text { Cacat } \\
\text { Tepung } \\
\text { Tinggi }\end{array}$} & \multirow[t]{2}{*}{ Manusia } & $\begin{array}{l}\text { Pekerja } \\
\text { kurang } \\
\text { disiplin }\end{array}$ & $\begin{array}{l}\text { Prose } \\
\mathrm{s} \\
\text { pellet } \\
\text { ing } \\
\text { kuran } \\
\mathrm{g} \\
\text { teram } \\
\text { ati }\end{array}$ & 4 & $\begin{array}{l}\text { Kurangny } \\
\text { a } \\
\text { keseriusan } \\
\text { dalam } \\
\text { bekerja }\end{array}$ & 4 & $\begin{array}{l}\text { Operator } \\
\text { diberitahu } \\
\text { dengan } \\
\text { cara } \\
\text { ditegur } \\
\text { dan } \\
\text { diperingat } \\
\text { kan karna }\end{array}$ & 4 & 64 \\
\hline & & $\begin{array}{l}\text { Kurang } \\
\text { nya } \\
\text { pengaw } \\
\text { asan }\end{array}$ & $\begin{array}{l}\text { Proses } \\
\text { pelleting } \\
\text { tidak } \\
\text { maksimal }\end{array}$ & 4 & $\begin{array}{l}\text { Operator } \\
\text { kurang } \\
\text { disiplin } \\
\text { dalam } \\
\text { penangana } \\
\text { n produk }\end{array}$ & 4 & $\begin{array}{l}\text { akan } \\
\text { berdampa } \\
\mathrm{k} \text { pada } \\
\text { perusahaa } \\
\mathrm{n}\end{array}$ & & \\
\hline & \multirow[t]{2}{*}{ Mesin } & $\begin{array}{l}\text { Dies } \\
\text { sudah } \\
\text { lama } \\
\text { terpakai }\end{array}$ & $\begin{array}{l}\text { Daya } \\
\text { tahan } \\
\text { (durability } \\
\text { ) pakan } \\
\text { ayam } \\
\text { menurun }\end{array}$ & 3 & $\begin{array}{l}\text { Diperluka } \\
\mathrm{n} \\
\text { pergantian } \\
\text { dies }\end{array}$ & 2 & $\begin{array}{l}\text { Diganti dan } \\
\text { dilakukan } \\
\text { perawatan } \\
\text { secara rutin }\end{array}$ & 3 & 18 \\
\hline & & $\begin{array}{l}\text { Saringa } \\
\mathrm{n} \\
\text { hammer } \\
\text { mill } \\
\text { bocor }\end{array}$ & $\begin{array}{l}\text { Tepung } \\
\text { tinggi } \\
\text { meningkat } \\
\text { Proses } \\
\text { mesin } \\
\text { menurun }\end{array}$ & 4 & $\begin{array}{l}\text { Gesekan } \\
\text { terus } \\
\text { menerus } \\
\text { Kecepatan } \\
\text { mesin } \\
\text { yang } \\
\text { tinggi }\end{array}$ & 3 & $\begin{array}{l}\text { Penggantia } \\
\mathrm{n} \text { saringan } \\
\text { yang bocor }\end{array}$ & 4 & 48 \\
\hline & \multirow[t]{2}{*}{ Material } & $\begin{array}{l}\text { Palm oil } \\
\text { tinggi }\end{array}$ & $\begin{array}{l}\text { Tidak } \\
\text { layak jual }\end{array}$ & 3 & $\begin{array}{l}\text { Timbanga } \\
\mathrm{n} \text { masih } \\
\text { manual }\end{array}$ & 3 & $\begin{array}{l}\text { Harus ada } \\
\text { takaran }\end{array}$ & 3 & 27 \\
\hline & & $\begin{array}{l}\text { Jagung } \\
\text { masih } \\
\text { basah }\end{array}$ & $\begin{array}{l}\text { Penghanc } \\
\text { uran } \\
\text { masih } \\
\text { menyisah } \\
\text { kan } \\
\text { banyak }\end{array}$ & 3 & $\begin{array}{l}\text { Kualitas } \\
\text { bahan } \\
\text { baku } \\
\text { kurang } \\
\text { baik }\end{array}$ & 2 & $\begin{array}{l}\text { Pengeringa } \\
\text { n ulang } \\
\text { jagung } \\
\text { dengan } \\
\text { dijemur }\end{array}$ & 2 & 12 \\
\hline
\end{tabular}




\begin{tabular}{|c|c|c|c|c|c|c|c|c|c|}
\hline \multirow{6}{*}{$\begin{array}{l}\text { Cacat } \\
\text { terdapat } \\
\text { pellet } \\
\text { pada } \\
\text { bentuk } \\
\text { crumble }\end{array}$} & Lingkungan & $\begin{array}{l}\text { Suar } \\
\text { a } \\
\text { mesi } \\
\mathrm{n} \\
\text { dan } \\
\text { getar } \\
\text { an } \\
\text { keras }\end{array}$ & $\begin{array}{l}\text { tepung } \\
\text { Operato } \\
\text { r tidak } \\
\text { fokus }\end{array}$ & 2 & $\begin{array}{l}\text { Saat } \\
\text { proses } \\
\text { produksi } \\
\text { suara } \\
\text { mesin } \\
\text { hidup } \\
\text { bersamaan }\end{array}$ & 3 & $\begin{array}{l}\text { Operator/ } \\
\text { karyawan } \\
\text { diwajibkan } \\
\text { memakai } \\
\text { penutup } \\
\text { telinga }\end{array}$ & 3 & 18 \\
\hline & \multirow[t]{2}{*}{ Manusia } & $\begin{array}{l}\text { Operato } \\
\text { r kurang } \\
\text { pas } \\
\text { dalam } \\
\text { menyete } \\
1 \text { mesin }\end{array}$ & $\begin{array}{l}\text { Terlalu } \\
\text { banyak } \\
\text { tepung } \\
\text { Terlalu } \\
\text { besar } \\
\text { pengaruh } \\
\text { ke pellet }\end{array}$ & 5 & $\begin{array}{l}\text { Pisau pres } \\
\text { tidak } \\
\text { otomatis }\end{array}$ & 4 & $\begin{array}{l}\text { Operator } \\
\text { harus } \\
\text { training } \\
\text { dalam } \\
\text { menyetel } \\
\text { mesin }\end{array}$ & 4 & 80 \\
\hline & & $\begin{array}{l}\text { Kurang } \\
\text { disiplin }\end{array}$ & $\begin{array}{l}\text { Pellet utuh } \\
\text { lewat } \\
\text { samping } \\
\text { mesin } \\
\text { masuk ke } \\
\text { shifter }\end{array}$ & 3 & $\begin{array}{l}\text { Gesekan } \\
\text { terus } \\
\text { menerus }\end{array}$ & 3 & $\begin{array}{l}\text { Operator } \\
\text { harus } \\
\text { ditegur } \\
\text { dalam } \\
\text { menyetel } \\
\text { mesin }\end{array}$ & 4 & 36 \\
\hline & \multirow[t]{2}{*}{ Mesin } & $\begin{array}{l}\text { Saringa } \\
\text { n hanya } \\
\text { satu }\end{array}$ & $\begin{array}{l}\text { Pellet bisa } \\
\text { lolos ke } \\
\text { tahap } \\
\text { akhir }\end{array}$ & 4 & $\begin{array}{l}\text { Proses } \\
\text { produksi } \\
\text { pakan } \\
\text { tidak } \\
\text { banyak }\end{array}$ & 5 & $\begin{array}{l}\text { Lapisan } \\
\text { saringan } \\
\text { ditambah }\end{array}$ & 5 & 100 \\
\hline & & $\begin{array}{l}\text { Setting } \\
\text { mesin } \\
\text { crumble } \\
\text { tidak } \\
\text { pas }\end{array}$ & $\begin{array}{l}\text { Terjadi } \\
\text { ketidakses } \\
\text { uaian } \\
\text { bentuk } \\
\text { crumble }\end{array}$ & 3 & $\begin{array}{l}\text { Operator } \\
\text { belum } \\
\text { pengalama } \\
\mathrm{n}\end{array}$ & 4 & $\begin{array}{l}\text { Operator } \\
\text { harus } \\
\text { pengalaman }\end{array}$ & 4 & 48 \\
\hline & Lingkungan & $\begin{array}{l}\text { Suar } \\
\text { a } \\
\text { mesi } \\
\mathrm{n} \\
\text { dan } \\
\text { getar } \\
\text { an } \\
\text { keras }\end{array}$ & $\begin{array}{l}\text { Operato } \\
\text { r tidak } \\
\text { fokus }\end{array}$ & 2 & $\begin{array}{l}\text { Saat } \\
\text { proses } \\
\text { produksi } \\
\text { suara } \\
\text { mesin } \\
\text { hidup } \\
\text { bersamaan }\end{array}$ & 3 & $\begin{array}{l}\text { Operator/ } \\
\text { karyawan } \\
\text { diwajibkan } \\
\text { memakai } \\
\text { penutup } \\
\text { telinga }\end{array}$ & 3 & 18 \\
\hline
\end{tabular}

Berdasarkan uraian tabel FMEA di atas, tahap terakhir adalah memberikan usulan rencana perbaikan sesuai urutan prioritas dari nilai RPN yang terbesar sampai yang terkecil. Berikut adalah usulan rencana perbaikan yang ditunjukkan pada tabel 4 . 
Tabel 4. Usulan rencana perbaikan (recommended action)

\begin{tabular}{|c|c|c|c|c|}
\hline No & $\begin{array}{l}\text { Component/ } \\
\text { Item } \\
\text { or Process }\end{array}$ & $\begin{array}{l}\text { Potential } \\
\text { Failure } \\
\text { Mode }\end{array}$ & $\begin{array}{c}\text { Potential Cause of } \\
\text { Failure }\end{array}$ & Recommended Action \\
\hline 1 & Mesin & $\begin{array}{l}\text { Saringan hanya } \\
\text { satu }\end{array}$ & $\begin{array}{l}\text { Proses produksi } \\
\text { pakan tidak banyak }\end{array}$ & $\begin{array}{l}\text { - Ditambahkan saringan pada } \\
\text { mesin crumble } \\
\text { - Melakukan perawatan dan } \\
\text { pemeriksaan secara rutin }\end{array}$ \\
\hline 2 & Manusia & $\begin{array}{l}\text { Operator kurang } \\
\text { pas dalam } \\
\text { menyetel mesin }\end{array}$ & $\begin{array}{l}\text { Pisau pres tidak } \\
\text { otomatis }\end{array}$ & $\begin{array}{l}\text { - Operator harus training } \\
\text { - Operator harus ditegur bila } \\
\text { melakukan kesalahan } \\
\text { - Lakukan inspeksi }\end{array}$ \\
\hline \multirow[t]{2}{*}{3} & Manusia & $\begin{array}{l}\text { Pekerja kurang } \\
\text { disiplin }\end{array}$ & $\begin{array}{l}\text { Kurangnya } \\
\text { keseriusan dalam } \\
\text { bekerja }\end{array}$ & $\begin{array}{l}\text { - Operator harus training } \\
\text { - Operator harus ditegur bila } \\
\text { melakukan kesalahan }\end{array}$ \\
\hline & & $\begin{array}{l}\text { Kurangnya } \\
\text { pengawasan }\end{array}$ & $\begin{array}{l}\text { Operator kurang } \\
\text { disiplin dalam } \\
\text { penanganan produk }\end{array}$ & - Lakukan inspeksi \\
\hline 4 & Mesin & $\begin{array}{l}\text { Saringan } \\
\text { hammer mill } \\
\text { bocor }\end{array}$ & $\begin{array}{l}\text { Gesekan terus } \\
\text { menerus }\end{array}$ & $\begin{array}{l}\text { - Diganti dan dilakukan perawatan } \\
\text { secara rutin } \\
\text { - Periksa kondisi mesin sebelum } \\
\text { dioperasikan }\end{array}$ \\
\hline 5 & Mesin & $\begin{array}{l}\text { Setting mesin } \\
\text { crumble tidak } \\
\text { pas }\end{array}$ & $\begin{array}{l}\text { Operator belum } \\
\text { pengalaman }\end{array}$ & $\begin{array}{l}\text { - Operator harus training secara } \\
\text { berkala } \\
\text { - Periksa kondisi mesin sebelum } \\
\text { dioperasikan } \\
\text { - Lakukan inspeksi }\end{array}$ \\
\hline 6 & Manusia & Kurang disiplin & $\begin{array}{l}\text { Gesekan terus } \\
\text { menerus }\end{array}$ & $\begin{array}{l}\text { - Operator harus training } \\
\text { - Operator harus ditegur bila } \\
\text { melakukan kesalahan } \\
\text { - Lakukan inspeksi }\end{array}$ \\
\hline 7 & Material & Palm oil tinggi & $\begin{array}{l}\text { Timbangan masih } \\
\text { manual }\end{array}$ & $\begin{array}{l}\text { - Penimbangan palm oil dilakukan } \\
\text { dengan mesin yang standar } \\
\text { - Lakukan inspeksi }\end{array}$ \\
\hline 8 & Mesin & $\begin{array}{l}\text { Dies sudah } \\
\text { lama terpakai }\end{array}$ & $\begin{array}{l}\text { Diperlukan } \\
\text { pergantian dies }\end{array}$ & $\begin{array}{l}\text { - Periksa kondisi mesin sebelum } \\
\text { dioperasikan } \\
\text { - Lakukan inspeksi } \\
\text { - Lakukan pergantian sesuai } \\
\text { ketentuan }\end{array}$ \\
\hline 9 & Lingkungan & $\begin{array}{l}\text { Suara mesin } \\
\text { dan getaran } \\
\text { keras }\end{array}$ & $\begin{array}{l}\text { Saat proses } \\
\text { produksi suara } \\
\text { mesin hidup } \\
\text { bersamaan }\end{array}$ & - Tidak ada \\
\hline 10 & Lingkungan & $\begin{array}{l}\text { Suara mesin } \\
\text { dan getaran } \\
\text { keras }\end{array}$ & $\begin{array}{l}\text { Saat proses } \\
\text { produksi suara } \\
\text { mesin hidup } \\
\text { bersamaan }\end{array}$ & - Tidak ada \\
\hline 11 & Material & $\begin{array}{l}\text { Jagung masih } \\
\text { basah }\end{array}$ & $\begin{array}{l}\text { Kualitas bahan } \\
\text { baku kurang baik }\end{array}$ & $\begin{array}{l}\text { - Memeriksa kembali bahan baku } \\
\text { yang diterima dengan lebih teliti } \\
\text { - Sesuai spesifikasi } \\
\text { - Memisahkan bahan baku yang } \\
\text { rusak/ cacat dengan bahan baku } \\
\text { yang berkualitas }\end{array}$ \\
\hline
\end{tabular}




\section{SIMPULAN}

Dengan menggunakan metode FMEA dapat diidentifikasi kerusakan pakan ayam dengan menghasilkan nilai Risk Priority Number (RPN) tertinggi yaitu untuk kerusakan terdapat pellet pada bentuk crumble. Untuk usulan rencana perbaikan yang harus dilakukan adalah di antaranya adalah melakukan pemeriksaan sebelum proses produksi, perlunya pengadaan pelatihan dan bimbingan yang tepat dan melakukan pengawasan yang ketat dan disiplin, serta memantau atau menginspeksi jalannya proses produksi.

Adapun beberapa saran yang dapat diberikan antara lain perusahaan diharapkan untuk mencoba melakukan atau mempraktekkan usulan rencana perbaikan dari metode FMEA agar dapat mengurangi kecacatan produk pada saat proses produksi berlangsung. Selain itu, perusahaan perlu memberikan arahan kepada pekerja atau operator sebelum memulai pekerjaan serta melakukan pengecekan menyeluruh pada kesiapan mesin sebelum produksi dimulai dan meningkatkan kesadaran akan mutu pada karyawan.

\section{DAFTAR PUSTAKA}

Assauri, Sofjan. 1993. Manajemen Produksi dan Operasi. Jakarta : Fakultas Ekonomi Universitas Indonesia.

Chase, Richard B., Nicholas J. Aquilano and F. Robert Jacobs. 2001. Operations Management For Competitive Adventage $9^{\text {th }}$ Edition. New York : McGraw-Hill Companies.

Heizer, Jay and Barry Render. 2006. Operations Management (Edisi Terjemahan). Jakarta : Salemba Empat.

Hofmann, A., \& Oldehaver, G. (2016). Vertically linked industries, product quality and minimum quality standards. German Economic Review, 17(1), 92-103.

Irianto, Drajat. 2010. Failure Mode \& Effect Analysis. Bandung : Manufacturing Systems Research Group ITB.

Kim, K. O., \& Zuo, M. J. (2018). General model for the risk priority number in failure mode and effects analysis. Reliability Engineering \& System Safety, 169, 321-329.

Klochkov, Y., Its, A., \& Vasilieva, I. (2016). Development of FMEA method with the purpose of quality assessment of can stock production. In Key Engineering Materials (Vol. 684, pp. 473-476). Trans Tech Publications.

Lawrence, X. Y., Akseli, I., Allen, B., Amidon, G., Bizjak, T. G., Boam, A., ... \& Furness, S. (2016). Advancing product quality: a summary of the second FDA/PQRI conference.

Liu, H. C. (2016). FMEA using uncertainty theories and MCDM methods. In FMEA using uncertainty theories and MCDM methods (pp. 13-27). Springer, Singapore.

Montgomery, Douglas C. 2001. Introduction to Statistical Quality Control. $4^{\text {th }}$ Edition. New York : John Willey \& Sons, Inc.

Moubray, John. 1997. Reliability Centered Maintenance. Second Edition. New York : Industrial Press Inc.

Nasution, M.N. 2005. Manajemen Mutu Terpadu. Bogor : Ghalia Indonesia.

Roy, S., Modak, N., \& Dan, P. K. (2017). Product quality as factors and measures for new product development success in Indian manufacturing industries. Materials Today: Proceedings, 4(2), 1385-1393.

Schroeder, Roger G. 2007. Manajemen Operasi. Jilid Dua Edisi Ketiga. Jakarta : Penerbit Erlangga.

Weckenmann, A., Akkasoglu, G., \& Werner, T. (2015). Quality management-history and trends. The TQM Journal, 27(3), 281-293. 
